\title{
Ganimedes en el diván. Una perspectiva histórica de la etiología de la homosexualidad masculina desde el psicoanálisis.
}

\author{
Danilo Magistrali ${ }^{1}$ \\ Madrid
}

La relación entre el psicoanálisis y la homosexualidad ha sido problemática y ambigua. El pensamiento psicoanalítico sobre la homosexualidad masculina probablemente estuvo más influido por las inclinaciones personales y culturales de los autores analíticos que otros temas. Este artículo pretende describir brevemente los principales aspectos de la historia de este conflicto y aclarar las razones de esta ambigüedad, en una revisión no exhaustiva.

Palabras clave: Homosexualidad, Etiología, Patología.

The relationship between psychoanalysis and homosexuality has been troublesome and ambiguous. Psychoanalytic thinking about male homosexuality was probably more culturally biased and influenced by the personal inclinations of analytical authors than other subjects. This article firstly aims to be a history of the main aspects of this conflict and secondly to clarify the reasons of this ambiguity, as a not exhaustive review.

Key Words: Homosexuality, Etiology, Pathology.

English Title: Etiology of male homosexuality according to psychoanalysis

\section{Cita bibliográfica / Reference citation:}

Magistrali, D. (2018). Ganímedes en el diván. Una perspectiva histórica de la etiología de la homosexualidad masculina desde el psicoanálisis. Clínica e Investigación Relacional, 12 (3): 479-512. [ISSN 1988-2939] [Recuperado de www.ceir.info ] DOI: 10.21110/19882939.2018.120305

\footnotetext{
${ }^{1}$ Danilo Magistrali es Licenciado en Química (Especialidad Físico-Química) (Pavía, Italia), DEA en Física de sistemas complejos (UC3M), y Doctorado en Fundamentos y desarrollos psicoanalíticos (F. Medicina UCM). Actualmente es profesor contratado de matemáticas y física en varias universidades (Ingeniería - U. Pontificia Comillas, E. Arquitectura - UPM, F.C. Económicas - UCM). Contacto: dmagistrali@icai.comillas.edu
} 


\section{El homosexual de Freud}

Freud fue ambiguo cuando, por un lado, declaró que los homosexuales no estaban enfermos e incluso defendió su derecho a convertirse en psicoanalistas y, por otro lado, desarrolló la base conceptual de una teoría etiopatológica que consideraba la homosexualidad un bloqueo en el desarrollo psicosexual de un individuo.

Ante de describir las teorías de Freud sobre la homosexualidad masculina es importante señalar que con Freud tenemos una ruptura epistemológica en el concepto de homosexualidad. A lo largo del siglo XIX podemos clasificar por lo menos tres maneras de conceptualizar la homosexualidad. La primera considera que la homosexualidad es una enfermedad de los órganos reproductivos o sexuales. La segunda insiste en que el instinto sexual puede comprenderse en términos de neurofisiología y neuroanatomía del cerebro. Estas dos maneras de pensar comparten un aspecto etiológico de tipo anatomopatológico La tercera manera de explicar la homosexualidad y las perversiones en general es considerarlas como desviaciones funcionales puras del instinto sexual, no reducibles a patología cerebral. Las perversiones pasaron a verse y a tratarse en el plano de la psicología.

Una categoría epistemológica común al pensamiento psiquiátrico decimonónico era el concepto de instinto sexual. La perversión se explicaba como una enfermedad funcional de este instinto. Podemos citar como ejemplo a Krafft-Ebing: «Physiologic life presents two instincts: that of self-preservation and that of sexuality. Abnormal life creates no new instincts, as was formerly erroneously supposed (the so-called instincts to murder, steal, and burn), but the natural instincts may be lessened, increased, or manifested with perversion.» (Kraft-Ebing, 1890, p.79).

Freud parte de las consideraciones de autores como Krafft-Ebing, Moll, Moebius, Havelock Ellis, Schrenck-Notzing, Löwenfeld, Eulenburg, Bloch, M. Hirschfeld. Autores que cita en los Tres ensayos. Ellos compartían una visión del instinto sexual en la que el objeto estaba entrelazado de manera profunda con el mismo instinto sexual. En este punto, Freud opera una ruptura epistemológica acerca del concepto de instinto. Para Freud «la pulsión sexual es al comienzo independiente de su objeto, y tampoco debe su génesis a los encantos de este» (Freud, 1905, p. 134). Esta afirmación de Freud rompe con el concepto de instinto sexual que compartían los psiquiatras del siglo XIX. Si el objeto no es interno al instinto, si no hay un objeto natural fisiológico entonces la clasificación de las anomalías del instinto pierde su fundamento. Freud introduce el concepto de pulsiones parciales que están relacionadas con sus zonas erógenas. Las fases parciales (oral, anal, fálica) funcionan de 
manera anárquica mientras que no se establezca la supremacía de la fase genital. El hecho de que la pulsión sexual está compuesta por pulsiones parciales conduce a la conclusión de que ni los genitales ni el coito tienen una relación privilegiada con el instinto sexual. La fase genital no es la esencia del instinto sexual. Para Freud, es inadmisible distinguir una pulsión homosexual particular; lo que define a los homosexuales no es una particularidad de la vida pulsional, sino de la elección de objeto. El concepto de Trieb está totalmente desvinculado del objeto. La pulsión freudiana es ciega, no tiene ni objeto ni finalidad teleológica. El Sexualtrieb freudiano no es el instinto sexual de Krafft-Ebing porque, para éste, el objeto y la finalidad sexuales eran vinculados al instinto. Entonces la homosexualidad no puede ser una enfermedad del instinto sexual porque la elección de objeto no forma parte de la pulsión freudiana. Si el psicoanálisis freudiano quiere buscar aspectos patológicos en la homosexualidad tiene introducir ideas extra psicoanalíticas en la nosología. Para Freud un deseo es patológico cuando por ejemplo es consecuencia de un bloqueo, cuando es de tipo narcisista o, para usar una terminología freudiana, cuando la investidura libidinal no es de tipo objetal. Este criterio nosológico, que es una importante aportación de Freud, no contempla el objeto sino el tipo de deseo que vincula al objeto. Un deseo homosexual puede ser de tipo narcisista o no, independientemente del objeto. En Freud se advierte esta tensión. Por un lado, declara más de una vez que los homosexuales no están enfermos y por otro lado desarrolla a lo largo de su obra varias teorías de tipo psicopatológico sobre la etiología de la homosexualidad.

Freud sostiene que la inversión es compatible con una identidad masculina, y que muchos homosexuales no presentan ninguna otra desviación grave respecto de la norma, que poseen un desarrollo intelectual y una cultura ética particularmente elevados. Freud suscribió en 1930 una petición pública para despenalizar la homosexualidad en Austria y Alemania. Mucho tiempo antes, en 1903, concedió una entrevista al diario de Viena Die Zeit, que estaba preparando un artículo de fondo acerca de un escándalo local: un destacado profesional vienés había sido procesado, acusado de prácticas homosexuales. Un periodista acudió a Freud para conocer su reacción, y Freud dijo que tenía la firme convicción de que los homosexuales no deben ser tratados como personas enfermas, ya que una orientación perversa está lejos de ser una enfermedad. Eso obligaría a caracterizar como enfermos a muchos grandes pensadores y eruditos a quienes admira. Es conocida también la respuesta que Freud escribió en 1935 a una madre americana preocupada por la homosexualidad de su hijo. Es interesante notar cómo Freud intenta analizar la resistencia de la madre a utilizar la palabra homosexual. Parece que intente más bien interpretar la vergüenza de la madre que dar consejos para "sanar" la homosexualidad del hijo. Es sorprendente la modernidad de la respuesta sobre la posible ayuda que puede dar el 
psicoanálisis al sujeto: no hay que cambiar su orientación sexual sino reducir los síntomas neuróticos en armonía con su identidad sexual tanto homosexual como heterosexual. También en otro momento Freud demostró una actitud abierta y moderna hacia la homosexualidad. Por ejemplo, sostenía que no había buenas razones para que a los homosexuales se les negara la solicitud a aspirantes a psicoanalistas. Esta posición se hizo evidente en 1920. La Asociación Holandesa de Psicoanálisis recibió la solicitud de un médico conocido por ser manifiestamente homosexual. Ante la duda, pidieron consejo a uno de los miembros del círculo más cercano a Freud, Ernest Jones, que escribiría más tarde su biografía y quien mantuvo a Freud informado del asunto. Freud consultó con otro miembro de su círculo íntimo y también amigo, Otto Rank. Luego ambos contestaron a Jones afirmando que no se puede excluir a los homosexuales sin tener otras razones complementarias. Además, Freud fue muy crítico acerca de la posibilidad de cambiar la orientación sexual de un paciente. Según él, la empresa de mudar a un homosexual declarado en un heterosexual no es mucho más promisoria que la inversa, sólo que esta última jamás se la intenta, por buenas razones prácticas. La postura de Freud hacia la homosexualidad es muy compleja. Por un lado, no asimila los homosexuales a los otros perversos y declara que no se pueden separar de las otras personas como un grupo que tiene una naturaleza especial. Por otro, considera que la homosexualidad es un bloqueo del desarrollo libidinal en una fase psicosexual que no ha llegado a la genitalidad.

Freud escribió sobre la homosexualidad a lo largo de su vida. Se pueden encontrar varias teorías y no siempre es fácil saber si está proponiendo una teoría nueva o la modificación de una antigua.

Una de las teorías de Freud más fáciles de entender acerca de la psicogénesis de la homosexualidad está directamente relacionada con el complejo de Edipo.

Cuando el niño sale de la fase narcisista empieza a experimentar angustia por la separación de la madre y al mismo tiempo tiene que lidiar con la angustia de castración que siente como castigo por los impulsos eróticos hacia ella. Cuando descubre que su madre no tiene pene, experimenta intensos sentimientos de miedo y de asco. Piensa que podría tener el mismo destino. La angustia de castración se hace intolerable. Busca una solución de compromiso en un hombre que tiene aspecto afeminado. Freud no puede ser más claro: «En quienes después serán homosexuales hallamos la misma preponderancia infantil de la zona genital, en especial del pene. Más aún: esta elevada estimación por el miembro masculino se convierte en destino para ellos. Escogen a la mujer como objeto sexual en su infancia mientras presuponen en ella la existencia de esta parte del cuerpo que reputan indispensable; cuando se convencen de que la mujer los ha engañado en este punto, ella se 
les vuelve inaceptable como objeto sexual. No pueden prescindir del pene en la persona destinada a estimularlos para el comercio sexual, y en el mejor de los casos fijan su libido en la «mujer con pene», el jovencito de femenina apariencia. Los homosexuales son, entonces, personas a quienes el significado erógeno de su genital propio les ha impedido renunciar en su objeto sexual a esta semejanza con la persona propia. En el desarrollo desde el autoerotismo al amor de objeto han permanecido fijados en un lugar más próximo al primero.» (Freud 1909 pp. 89-90). Esta teoría es la consecuencia de los trabajos de Freud acerca del desarrollo psicosexual que empezó en el periodo de los Tres ensayos. En este sentido, la homosexualidad representa una posible respuesta a la angustia de castración. De cierta manera, la homosexualidad es muy parecida a nivel psicogenético al fetichismo. Los dos representan una respuesta al horror que el niño experimenta delante de la ausencia de pene de la madre. El homosexual responde al deseo de una mujer con pene buscando hombre afeminados, el fetichista busca mujeres pero sigue pensando, de manera inconsciente, que tengan un pene. El fetiche es un sustituto del pene. "Si ahora comunico que el fetiche es un sustituto del pene, sin duda provocaré desilusión. Por eso me apresuro a agregar que no es el sustituto de uno cualquiera, sino de un pene determinado, muy particular, que ha tenido gran significatividad en la primera infancia, pero se perdió más tarde. Esto es: normalmente debiera ser resignado, pero justamente el fetiche está destinado a preservarlo de su sepultamiento (Untergang) - Para decirlo con mayor claridad: el fetiche es el sustituto del falo de la mujer (de la madre) en que el varoncito ha creído y al que no quiere renunciar» (Freud, 1027, p.147).

Según esta concepción, la homosexualidad tiene claros rasgos psicopatológicos, así como los tiene el fetichismo. Ya sabemos que para Freud el desarrollo sexual sano se verifica cuando las fases psicosexuales se reorganizan bajo el dominio de la fase genital. Si el sujeto se queda atrapado en una fase anterior del desarrollo libidinal, allí tenemos una psicopatología.

Además, para Freud, el homosexual sigue deseando de manera inconsciente a la mujer pero ha tenido que reprimir este deseo por miedo a la castración. En este sentido el deseo homosexual no es primario, sino una formación de compromiso para tolerar la angustia de castración. Cuando el niño alcanza la fase edípica, acaba de superar la fase anal del narcisismo y entra en la fase fálica justo antes de invertir energía libidinal hacia los verdaderos objetos relacionales. Durante la fase fálica las relaciones objetales son aún inestables. Todos los niños viven el trauma de descubrir que la madre no tiene pene, pero los heterosexuales seguirán buscando objetos satisfactorios después de haber elaborado el complejo de Edipo durante la pubertad. 
Freud presenta otra teoría que no es incompatible con la primera, aunque es distinta. La describe por primera vez en los Tres ensayos y la repite otras veces por ejemplo en la monografía sobre Leonardo o en el artículo acerca de las relaciones entre celos, paranoia y homosexualidad. Según esta teoría, el sujeto homosexual ha tenido una relación con la madre particularmente larga, de manera que supervalora su pene. El niño no quiere reprimir esta relación con ella probablemente porque la madre tiene un excesivo apego a él. Freud no explica la razón por la cual el niño interrumpe este enlace; en lugar de reprimirlo completamente, lo preserva inconscientemente: ahora se identifica con la madre y busca objetos de amor que se parezcan a él. Mientras que desea a estos objetos reactualiza la experiencia erótica que había tenido con la madre. Ahora puede amar y ser amado, amando a la madre que ha introyectado. Antes era amado y ahora ama a un objeto, pasando de pasivo a activo. El Yo del homosexual es así modelado a través de la imagen de la madre. «Todos nuestros varones homosexuales habían mantenido en su primera infancia, olvidada después por el individuo, una ligazón erótica muy intensa con una persona del sexo femenino, por regla general la madre, provocada o favorecida por la hiperternura de la madre misma y sustentada, además, por un relegamiento del padre en la vida infantil. Sadger ha destacado que la madre de sus pacientes homosexuales era a menudo un marimacho, una mujer con enérgicos rasgos de carácter, capaz de expulsar al padre de la posición que le corresponde; en ocasiones yo he visto lo mismo, pero he recibido una impresión más fuerte de aquellos casos en que el padre faltó desde el comienzo o desapareció tempranamente, de suerte que el varoncito quedó librado al influjo femenino. De todos modos, parece como si la presencia de un padre fuerte asegurara al hijo varón, en la elección de objeto, la decisión correcta por alguien del sexo opuesto.»|cite[pág. 92]\{freudig1ob\}

Estas dos teorías parecen opuestas porque la primera es una renuncia consciente al enlace con la madre mientras que la segunda es la preservación inconsciente de este enlace. En la primera, el niño rechaza a las mujeres para aliviar el odio y el horror hacia la madre, mientras que en la segunda huye de ellas para garantizar su fidelidad hacia la madre. Estos dos mecanismos parecen complementarios y conducen a la formación de un complejo compromiso que permite al niño, por un lado, huir de la angustia de castración y, por el otro, mantener una gratificación libidinal con la madre. Esta teoría implica muchos factores patológicos. El más importante es la introyección de la figura materna y la creación de un yo que no corresponde a la identidad biológica del niño.

«La génesis de la homosexualidad masculina es, en una gran serie de casos, la siguiente: El joven ha estado fijado a su madre, en el sentido del complejo de Edipo, durante un tiempo y con una intensidad inusualmente grandes. Por fin, al completarse el proceso de la 
pubertad, llega el momento de permutar a la madre por otro objeto sexual. Sobreviene entonces una vuelta (Wendung) repentina; el joven no abandona a su madre, sino que se identifica con ella; se trasmuda en ella y ahora busca objetos que puedan sustituirle al yo de él, a quienes él pueda amar y cuidar como lo experimentó de su madre ... Llamativa en esta identificación es su amplitud: trasmuda al yo respecto de un componente en extremo importante (el carácter sexual), según el modelo de lo que hasta ese momento era el objeto.» (Freud, 1920, p. 102).

Freud desarrolló una tercera teoría en el estudio de caso del Hombre de los lobos que se conoce popularmente como el complejo de Edipo negativo o invertido, y sus mecanismos son, paradójicamente, tanto provocados como terminados por el Complejo de Edipo. Curiosamente, Freud describió esta teoría en la historia del caso de alguien que no era homosexual, después de haber investigado una fase del desarrollo psicosexual que aún permanecía presente en el inconsciente.

Esta forma particular de homosexualidad es más común que las otras y se puede encontrar, por ejemplo, en las transferencias en la terapia de pacientes que no son principalmente homosexuales. Es importante porque anticipa con gran agudeza las controvertidas nociones de actividad y pasividad, así como la de bisexualidad.

En este caso particular, la previa identificación del hombre de los lobos con el padre se deshizo cuando una hermana mayor lo sedujo. La posición libidinal del niño, que ya tendía a una masculinidad más bien narcisista, pasó entonces de una forma masculina, activa y fálica a una femenina, pasiva y anal. El padre, que sirvió una vez como base para una identificación masculina, luego se convirtió en objeto de amor del niño. En lugar de ser como el padre, el niño eligió ser amado por él. Además, el niño relaciona un ataque de disentería de su madre con una escena primitiva realizada more ferorum ab tergo (a la manera de las bestias, desde la parte posterior) de la cual fue testigo, que aumenta sus celos hacia la madre y la hermana y da lugar a una nueva identificación con la madre y a un cambio de zona erógena primaria hasta el ano. Por lo tanto, se mostró dispuesto a debilitar su identidad masculina con el fin de ser amado como una mujer (Freud, 1918, p.40). Freud interpretó el deseo del hombre de los lobos de volver al vientre de su madre como una superposición de deseos homosexuales y heterosexuales. Por un lado, representa el deseo de estar dentro de los genitales de la madre, porque el niño se imagina a sí mismo como un pene. En este sentido la fantasía de renacimiento es, ante todo, un símbolo para tener relaciones sexuales con la madre. Por otro lado, el deseo de estar en el vientre de la madre también representa el deseo de copular con el padre y entregarle un niño. 
En una cuarta teoría, al igual que en los otros casos, hay un intenso amor hacia la madre, acompañado de intensos celos hacia los hermanos, así como hacia el padre. Estos celos movilizan deseos de muerte y fantasías sádicas de gran violencia. No está claro lo que obliga al niño a renunciar y transformar estos deseos. Sin embargo, bajo la influencia de la educación, estos deseos de muerte son reprimidos y transformados en sentimientos de amor homosexual a través de un proceso que Freud llamó formación reactiva.

«Estos celos provocaban actitudes intensamente hostiles y agresivas hacia los hermanos, que podían extremarse hasta desearles la muerte; empero, sucumbían en el proceso de desarrollo. Bajo los influjos de la educación, y sin duda también por la continua impotencia de estas mociones, se llegaba a su represión y a una trasmudación de sentimientos, de suerte que los que antes eran rivales devenían ahora los primeros objetos de amor homosexual» (Freud 1922, p. 225). En el caso de la paranoia, el impulso homosexual intolerable, Lo amo, es transformado por negación en Lo odio, y luego a través de la racionalización proyectiva en Él me odia, por lo que la paranoia evita que el sujeto se convierta en homosexual. Por otra parte, esta teoría explica la notable correspondencia entre la homosexualidad y los sentimientos sociales altamente desarrollados y el altruismo, ya que el mecanismo de formación de la reacción transforma fantasías asesinas en impulsos sociales.

La última postura teórica que podemos hallar en el pensamiento de Freud no es una verdadera teoría acerca de la etiología de la homosexualidad, sino una actitud intelectual y moral. La mayoría de las veces, Freud considera la homosexualidad una patología, en el sentido de una fijación a una fase del desarrollo psicosexual. Sin embargo, a veces afirma que no puede ser considerada como una enfermedad, sino como una variante de la función sexual (Jones, 1953, p. 195). En los Tres Ensayos escribe que se halla «la inversión en personas que no presentan ninguna otra desviación grave respecto de la norma. [...] es preciso considerar que, en pueblos antiguos, en el apogeo de su cultura, la inversión fue un fenómeno frecuente, casi una institución a la que se confiaban importantes funciones.» (Freud 1905, p. 126). Freud parece avanzar la hipótesis de que la homosexualidad es una variante normal de la sexualidad y destruye las nociones convencionales de orientación sexual. Enfatiza la ubicuidad de la fantasía y del deseo sexual polimorfo y subraya la dificultad de trazar una línea exacta entre lo que es normal y lo que patológico. En la carta a la madre americana de 1935 Freud afirma claramente que «homosexuality is assuredly no advantage, but it is nothing to be ashamed of, no vice, no degradation, it cannot be classified as an illness» (Freud, 1935). Incluso llega a decir que todo ser humano es capaz de una elección de objeto de tipo homosexual y que los deseos homosexuales tienen un papel importante en la formación de la vida sexual normal: «La investigación psicoanalítica se 
opone terminantemente a la tentativa de separar a los homosexuales como una especie particular de seres humanos. En la medida en que estudia otras excitaciones sexuales además de las que se dan a conocer de manera manifiesta, sabe que todos los hombres son capaces de elegir un objeto de su mismo sexo, y aun lo han consumado en el inconsciente. Por otra parte, los sentimientos libidinosos en vinculación con personas del mismo sexo no desempeñan escaso papel como factores de la vida sexual» (Freud, 1905, p. 132). Anticipando las teorías de género, pone en duda la normatividad de la orientación heterosexual. En una nota agregada en 1915, leemos: «En el sentido del psicoanálisis, entonces, ni siquiera el interés sexual exclusivo del hombre por la mujer es algo obvio, sino un problema que requiere esclarecimiento.» (Freud, 1905, p. 132).

Más significativa es una carta que Freud envió a Fliess en el 1899, donde afirma que la homosexualidad podría ser la forma primitiva de la sexualidad "¿Qué dirías si la masturbación se redujese a la homosexualidad, y esta última, es decir la homosexualidad masculina (en ambos sexos) fuese la forma primitiva del deseo sexual?» (Freud 1999, p. 408). Merece la pena recordar que para Freud un analista podía ser homosexual. Una postura que la Sociedad Psicoanalítica no tomó en cuenta a la hora excluir los candidatos homosexuales. Habría que esperar hasta 1991 cuando la American Psychoanalytic Association (APsaA) aprobó un documento donde reprochaba toda discriminación pública y privada hacia las personas homosexuales, e invitaba sus institutos a seleccionar candidatos no según su orientación sexual sino de acuerdo con su interés para el psicoanálisis, preparación cultural, integridad psicológica y analizabilidad.

\section{La primera generación: el triunfo de Edipo.}

La primera fase del pensamiento psicoanalítico sobre la homosexualidad se inició evidentemente con Freud y tiene contribuciones de algunos de sus primeros discípulos: Isidor Sadger y Felix Boehm se interesaron por el problema de la homosexualidad en varios artículos. Otto Rank y Hanns Sachs intentaron integrar las perversiones sexuales dentro de una teoría psicoanalítica más general y Sandor Ferenczi propuso una primera nosología seria de la homosexualidad. No nacen nuevas teorías, sino que se consolidan las teorías freudianas.

Muchos de los primeros analistas compartían con Freud una actitud tolerante hacia la condición homosexual. Por ejemplo, aunque Brill pensaba que la homosexualidad estaba estrechamente relacionada con el amor propio y que el camino hacia la homosexualidad siempre pasaba a través del narcisismo, sin embargo, sostenía que la cuestión de la elección de objeto era esencialmente independiente de cualquier noción de psicopatología. Para él, 
la homosexualidad puede encontrase en personas tan saludable como las personas heterosexuales normales. En su artículo de 1913 Brill es muy moderno y merece la pena leer directamente sus palabras: «a large number of homosexuals are in no way abhorrent of themselves in respect to their natures; they seem to be perfectly happy and perfectly well adjusted, probably in a restricted sense, and these patients probably are not worth while treating as Dr. Brill treats them. If we accept homosexuality as a condition which has as much right to exist as heterosexuality, why should we address ourselves to the duty of treating it?» (Brill, 1913, p. 335)

Estos primeros analistas estudiaron la homosexualidad persiguiendo tres finalidades: confirmar las ideas de Freud; aportar nuevo material clínico; y generalizar estas ideas a otros ámbitos como el arte, la antropología, o la educación. Cualquier avance teórico, como la formación del superyó, las subetapas de la fase fálica, o la teoría general de las perversiones, era periférico en la teoría analítica de la homosexualidad. Estos autores dieron las primeras contribuciones a varios debates en torno a la cuestión de si la homosexualidad era un fenómeno unitario, a la clasificación de la homosexualidad, y a la cuestión técnica del tratamiento, del pronóstico y de la curación.

Muchos analistas negaron por completo la importancia de factores hereditarios en la etiología de la homosexualidad. Ferenczi, por ejemplo, no creía en la homosexualidad innata. La constitución sexual es algo potencial. Llegó a sostener que la elección de objeto homosexual es la reacción a una heterosexualidad excesivamente poderosa intolerable para el yo (Ferenczi, 1909). Se sostenía que ciertas tendencias podían considerarse innatas, pero no una tendencia específica hacia la homosexualidad o la heterosexualidad. Más bien características tales como una tendencia al narcisismo, entendido como opuesto a la elección de objeto, que al actuar a través de situaciones familiares accidentales podía afectar a la elección sexual o a las identificaciones con cada una de las figuras parentales. Al final de los años Veinte, ningún analista sostenía una relación directa entre los factores constitucionales y la elección de objeto sexual.

Cabe recordar que George Henry, un psiquiatra, publicó un artículo sobre los factores psicógenos de la homosexualidad. Henry no pertenecía al campo psicoanalítico, pero hacía referencia a las teorías freudianas. Interesado principalmente en la profilaxis, enumeró diez generalizaciones. Pensó que la homosexualidad se debía en gran parte a factores constitucionales y al ambiente, y sugirió tomar un historial familiar que remontase al menos a los abuelos, no como una forma de evaluar una degeneración genética, sino como una manera de explorar conjuntos de relaciones emocionales en la familia. «Prolonged, intense emotional reactions to parents, and sexual traumata in childhood are rare in the 
heterosexually adjusted while these reactions and traumata are frequently noted in the early lives of homosexual individuals. In addition, when personality disorders occur the heterosexuals tend to develop benign psychoses while the homosexuals are prone to have chronic paranoic and schizophrenic illnesses. It would seem therefore that any intrusion of adult sexuality in childhood is distinctly unhygienic (Henry 1934, p. 264). El autor apoya el concepto de bisexualidad primordial. Hay que recordar que las conclusiones de Henry se basaban en el estudio de 250 pacientes que habían estado en un hospital psiquiátrico durante por lo menos tres meses.

La tarea de los primeros analistas varió desde confirmar la más grande de las ideas de Freud, la importancia crucial del complejo de Edipo, hasta confirmar sus nociones bastante más detalladas y técnicas, tales como la naturaleza exacta y el alcance del erotismo anal. Sadger, por ejemplo, pensaba que el complejo de Edipo era un elemento central en el desarrollo de la elección de objeto homosexual, e hizo hincapié en los deseos de castración dirigidos contra el padre, y señaló la identificación con la madre y la elección de un objeto de amor como un sustituto del yo. Para Sadger, el homosexual es fijado en su madre. Boehm hace un resumen de las ideas de Sadger en un artículo del 1921. "Sadger summarises his new experiences on male inversion in his article Neue Forschungen zur Homosexualität as follows: 1) the urning behaves towards female sexual objects like the psychically impotent person who is incapable because he is fixed on his mother or more rarely his sister; 2 ) a part of his specific constitution lies in the fact that, on the one hand, his muscle erotism is diminished from the outset, while on the other hand, his genital libido and the sexual pleasure in looking - this latter being particularly directed to the sex organs - are considerably increased; 3) very frequently the already over-strong genital libido is further increased by stimuli coming from the father who loves his offspring to excess; 4) an over-estimation of the male genital pursues the urning like a demon; 5) for similar reasons there exists a particular pleasure in handling the penis. The typical 'corruptors' are for the most part 'absolutely' homosexual; 6) the over-emphasis of the genital libido without exception leads to early amourousness towards the opposite sex, above all the mother or her early representative; 7) the mother's sharp repulse occasions his first disappointment; the second is the missing of the penis in the mother, which he feels more acutely than normal children; 8) when in maturity he again experiences a disappointment in sexualibus through the mother, he becomes fixed on his own sex by means of regression to the primarily loved mother with the penis; 9) this regression enables him to give and receive the two strongest sensations of love of every man, i. e. love of the mother and of the ego. This accounts for the urning's fixation on the man.» (Boehm 1921, p. 446). 
Sachs desarrolló y perfeccionó la idea de Freud de que las perversiones representan la resistencia de una parte de la sexualidad infantil hacia el desarrollo completo de la genitalidad. Lo que distingue las perversiones de las neurosis es la calidad egosintónica de la tendencia perversa con respecto al yo, es decir, la ausencia en ellas de culpa o ansiedad. Según Sachs, los componentes de la sexualidad infantil se someten a un tipo de refracción a través del complejo de Edipo, en el que uno de los componentes se escapa de la represión y entra en el yo al servicio de la represión de las otras componentes. Las perversiones no son indiferenciadas y primitivas como podría sugerir la teoría de Freud, sino que pueden ser muy elaboradas y diferenciadas.

La angustia de castración como causa de la homosexualidad es importante en el pensamiento de Rank: «Among other causes for the fixation of inversion we are familiar with the simple mechanism of what is called the flight from incest, which is naturally founded on a particular attitude, possiblyalso on a particular predisposition, and leads to alienation from the opposite sex and to an attachment to objects of the same sex ... I can personally confirm only one fundamental mechanism, that which we call defence against incest, which out of the original normal sexual type of Oedipus-attitude and by means of the emotional interplay of love and hate towards both sexes - father and mother - gives an appearance of a homosexual affective fixation. This can be resolved by making conscious the sense of guilt motivating it and by the abreaction of it» (Rank 1922, p. 274).

Ferenczi presenta en 1914 una importante nosología de la homosexualidad masculina. Acepta la teoría de la bisexualidad originaria de todo ser humano y considera que el complejo narcisista es la base de la homosexualidad: «todo ser humano atraviesa en realidad por un estadio psíquico bisexual durante su infancia» (Ferenczi 1914, p. 444). Ferenczi usa la teoría de Freud del Edipo negativo para explicar la génesis del homosexual tipo sujeto, es decir el homosexual que ha adaptado su yo al yo de la madre.

Felix Boehm subraya la importancia de la fantasía de que el pene del padre haya sido retenido por la madre después de la cópula y está oculto dentro de su vagina. Boehm habla de penes femeninos ocultos que ejercen una influencia patológica en virtud del hecho de que se ponen en una relación inconsciente con la idea de un pene grande y temido, perteneciente al padre, que está oculto en el interior de la madre.

Boehm ha dirigido su atención al papel desempeñado por ese aspecto del complejo de Edipo, que consiste en el odio del niño hacia su padre y sus deseos de muerte y castración en su contra. En la realización de los actos homosexuales, el varón, con mucha frecuencia, tiene dos objetivos: 1) hacer impotente a su rival para que pueda llevar a cabo el acto heterosexual, en cuyo caso es, sobre todo, una mera cuestión de mantenerlo alejado de las 
mujeres, y 2) castrarlo, en cuyo caso él quiere tomar posesión del pene de su pareja, con el fin de aumentar su potencia sexual con las mujeres. Para Boehm, la homosexualidad no es un fenómeno constitucional, sino un problema puramente psicológico, que es curable. Los homosexuales tienen un fuerte componente sádico-anal y se fijan en una etapa de desarrollo narcisista. La homosexualidad tiene sus raíces en las vicisitudes del complejo de Edipo, como ocurre en todas las otras perversiones. Muchos autores de la primera generación coincidieron en la importancia crucial que tiene el narcisismo en el desarrollo de la elección de objeto homosexual.

Para Wilhelm Reich, la función básica de todo ser vivo es la orgásmica. Reich cuestionó la función reproductiva generalmente atribuida al orgasmo desde la biología, reemplazándola con una energía que resultaría en el dualismo tensión-erección y descargaeyaculación. Reich creía que la descarga de la energía sexual era una necesidad para preservar las funciones biológicas del organismo. A pesar de ser un exponente de la liberación sexual, las opiniones de Reich sobre la homosexualidad son bastante conservadoras. Aunque siempre predicó que el comportamiento sexual no puede ser juzgado por normas morales, sino sólo por las normas de la salud o de la enfermedad, no estaba totalmente libre de juicios morales acerca de la sexualidad. Por ejemplo, tenía una doble moral sobre la homosexualidad. Para Reich, la homosexualidad es una neurosis en sí misma y el placer que deriva de un acto homosexual es inferior al placer heterosexual. Para Reich, la homosexualidad tiene que ser curada y es un fenómeno social que puede prevenirse a través de una correcta educación sexual. Reich concluye «that homosexuality is a purely social phenomenon, i.e., a question of sexual education and development. The best means of preventing it is to bring up and educate the two sexes side by side and to permit sexual intercourse to commence at the right time.» (Reich 1932, p. 201) También para Reich, como para los autores de este periodo, la homosexualidad pertenece al reino de las neurosis.

Gran parte de los primeros escritos sobre la homosexualidad no se referían específicamente a la homosexualidad, sino a la paranoia. Surgió así la idea de que había una conexión entre homosexualidad y paranoia en el sentido de que en muchos homosexuales la orientación sexual era una defensa paranoica. La mayoría de los psiquiatras que trataban de adoptar un punto de vista analítico tenían un contacto limitado con homosexuales que no sufrieron algún trastorno paranoide. Estudiaban personas perturbadas, que presentaban conflictos internos debidos a la homosexualidad.

Según Fenichel, los hombres homosexuales tienen miedo a los genitales femeninos. Para ellos, la visión de una mujer sin pene es tan aterradora que evitan cualquier relación sexual 
con ella. La visión de los genitales femeninos puede despertar ansiedad en un niño de dos maneras: 1) el reconocimiento del hecho de que en realidad hay seres humanos sin un pene lleva a la conclusión de que podría tener el mismo destino; tal observación da fuerza a las amenazas de castración; 2) como ha señalado Karen Horney, los órganos genitales femeninos, a través de la conexión de la angustia de castración con viejas ansiedades orales, pueden ser percibidos como un instrumento castrador capaz de morder o arrancar el pene. Fenichel cree que un buen número de hombres homosexuales se identifican con una madre agresora. Después de esta identificación, el desarrollo psíquico puede ir en varias direcciones. El sujeto más narcisista se esfuerza, en primer lugar, por asegurarse un sustituto a su angustia edípica. Elige como como objeto de amor a jóvenes que son similares a él mismo, y los ama y los trata con la ternura de su madre. Por lo tanto, goza del placer de ser amado por sí mismo. Los sujetos narcisistas están enamorados de ellos mismos y de sus penes, son caracteres fálicos. Les gustan los chicos adolescentes, quienes son una representación de ellos mismos en el momento de su propia adolescencia. El cuadro clínico es muy diferente si, a raíz de la identificación con la madre, una fijación anal determina el desarrollo posterior. El deseo de gratificación sexual con la madre se transforma en el deseo de disfrutar de la misma manera en que lo hace ella. El padre se convierte en el objeto del amor, y el individuo se esfuerza por someterse a él de una manera pasivo-receptiva. Ésta es la base para el desarrollo de los individuos homosexuales de objeto. En tales casos, el complejo de Edipo se resolvía mediante la asunción del Edipo invertido. La sumisión pasiva al padre esconde la idea inconsciente de robarle su masculinidad. En realidad, los hombres no han renunciado del todo a su masculinidad. Inconscientemente, consideran su feminidad como algo temporal, son parejas femeninas de un hombre masculino para aprender los secretos de la masculinidad del maestro, y robarle esos secretos. En tales casos, la sumisión pasiva al padre se combina con una identificación oral hacia él.

Había un acuerdo general de que la homosexualidad era un aspecto de una bisexualidad básica y universal, que seguía siendo un principio fundamental de la teoría psicoanalítica. Eduard Hitschmann fue probablemente el primero en dar una presentación sistemática del pensamiento de Freud en 1911. Para Hitschmann, también la homosexualidad se podía entender sólo a partir de la bisexualidad original del ser humano: «A satisfactory explanation of inversion is afforded only by the perception that there is in every one an original bisexual tendency which is also established anatomically.» (Hitschmann 1911, p. $60)$.

En este periodo, una minoría de los psicoanalistas era propensa a ver la homosexualidad como una condición casi psicótica, y sólo a partir de los años 40 muchos verán la 
homosexualidad como consecuencia de una estructura de personalidad tipo borderline caracterizada por relaciones de objeto primitivas.

En un libro póstumo publicado en 1942, Paul Schilder da una visión de la homosexualidad muy moderna. En primer lugar, describe los aspectos más típicos de la homosexualidad apoyándose en los resultados freudianos. Según él, los rasgos comunes más típicos son: a) la rivalidad con el padre y el hermano; b) negligencia por parte de la madre; $c$ ) identificación con la madre; d) amor hacia el hermano y hacia el padre; e) pasividad hacia el padre, el hermano, o hacia la mujer; f) sobrevaloración de la región anal, en relación con la pasividad; g) la fantasía de que la madre tenga un pene; h) la madre como objeto de amor (mujer con un pene o un sustituto simbólico); i) el padre (hombre) como objeto de amor activo o pasivo; j) el objeto de amor homosexual es más fácil de alcanzar que el objeto de amor heterosexual, difícil y peligroso.

Schilder no está interesado en la homosexualidad como «a clinical entity but with those socalled homosexual trends found in every human being and forming an important part in their attitudes towards sex.» (Schilder 1942, p. 156)

El intento de los seres humanos de orientarse en relación a los roles y a las funciones sexuales es un acto altamente social. La orientación relativa al sexo no puede ser el acto de un individuo aislado, incluso en lo que respecta a sus propias partes sexuales, y menos aún en lo que respecta a las partes sexuales de otra persona. Incluso se podría aventurar la afirmación de que el carácter social general de la experiencia humana tiene una de sus expresiones más claras en el sexo y en el conocimiento acerca de sexo. Schilder llega a dudar de que la heterosexualidad sea la tendencia básica del individuo. El autor no ve una diferencia entre los procesos psíquicos de los heterosexuales y de los homosexuales.

\section{Factores preedípicos}

Durante los años treinta hubo un aumento del interés hacia las fases preedípicas, en particular la fase oral. También la homosexualidad fue interpretada de acuerdo con los nuevos aportes teóricos de la escuela de las relaciones objetales. La homosexualidad pasó de ser una neurosis a ser una perversión, aunque fuera la más desarrollada. El aspecto más importante de este periodo fue el desplazamiento de interés por los conflictos a nivel edípico a los de la etapa oral más primitiva. Se pensaba que la heterosexualidad era el resultado final natural del desarrollo psicosexual.

La homosexualidad no era una mera variante del desarrollo, como implícitamente era para Freud, sino el resultado de un trauma. Se reforzó la convicción de que la unión primaria para 
todos los hombres era con la madre y, en particular, con el seno materno. La descripción de los rasgos del carácter homosexual también se hizo marcadamente oral: los analistas destacaron el masoquismo, el odio oral y el empaparse de la libido con la agresión. Hasta los años treinta, algunos analistas se planteaban si existían formas de homosexualidad no perversa. Posteriormente, casi todos coincidían en que la homosexualidad era una perversión. Algunos autores llegaron a afirmar que la verdadera homosexualidad depende de una fijación oral, mientras que la homosexualidad espuria es consecuencia del Edipo negativo. "Whereas the true homosexual is fixated on the oral stage, the spurious homosexual, a hysterical neurotic, identifies himself unconsciously with the passive mother of the oedipal period and is fixated on the stage of the negative Oedipus complex. The objection of the superego to the passive wishes compels the merely passive feminine man to unconscious defence in order to refute the accusations of the inner conscience. He produces a compensatory he-man attitude, admittedly of a capricious and not very high potency. The compensatory mechanism, however, does not always function so well; the defence is sometimes weak and this type of man passes for effeminate and, incorrectly, for homosexual. There exists, as may often be observed, a type of homosexual who imitates women and is considered simply as the homosexual [...] the genuine homosexual usually seeks refuge in his man-to-man relationship to escape his repressed masochistic attachment to the pre-oedipal mother» (Winterstein 1956, p. 301).

El desplazamiento de los sentimientos de odio y de ansiedad desde pene del padre al cuerpo de la madre se postulaba muy importante, según Melanie Klein, en la etiología de los trastornos mentales y es un factor subyacente en el desarrollo sexual y en la adopción de una actitud homosexual en el individuo masculino. El miedo del pene imaginario de la madre era un paso intermedio en este proceso de desplazamiento. De esta manera, desplaza el temor al pene del padre dentro de la madre, un miedo que es insoportable, porque en esta etapa temprana del desarrollo es válido el principio de pars pro toto y el pene representa al padre. Además, la fijación oral de succionar el pene del padre es un factor primordial en el establecimiento de una verdadera homosexualidad. En el análisis de algunos niños, Klein rastrea el desarrollo anormal de un sadismo excesivamente fuerte. Como consecuencia, hay un debilitamiento del principio de realidad y la producción de severos rasgos obsesivos y paranoides. El refuerzo de los impulsos libidinales y de los componentes homosexuales que tienen lugar en estos niños sirve para alejar y modificar el temor a su padre, que había aparecido tan temprano en ellos. Este modo de hacer frente a la ansiedad es un factor etiológico fundamental en la homosexualidad de los paranoicos. (Klein 1932, p. 225). 
Melanie Klein considera la fase oral como principal determinante de la homosexualidad. En su trabajo analítico con los niños, había encontrado que la fijación oral afectaba a las fases post-orales del desarrollo psicosexual, no sólo en el sentido de que son elementos que contribuyen a la fase genital, sino como determinantes de la naturaleza de la organización genital. Por ejemplo, las frustraciones orales en el niño producían fantasías de canibalismo tanto hacia el pecho de la madre como hacia la totalidad de ella. Debido a esto, el niño proyecta estos sentimientos y fantasías de manera que ve al mundo externo como canibalista y desarrolla miedo a los objetos. Esto produce miedo a ser devorado por el objeto amado. La vagina, que inconscientemente se equipara con la boca, viene a representar el órgano castrador y devorador. Tales equiparaciones dan como resultado que se evite el objeto heterosexual y solamente se permite una relación con un hombre porque el genital masculino, que representa el pecho, produce seguridad. Las causas de la homosexualidad fueron extendidas por Klein a niveles más tempranos del desarrollo respecto a los conceptualizados por Freud. Si el miedo del niño hacia el cuerpo peligroso de la madre es muy fuerte y no es capaz de desarrollar la imagen de una madre buena, sus fantasías de aliarse con el padre en contra de la madre o de aliarse con los hermanos en contra de ambos padres, lo inclinan a establecer una posición homosexual.

Nunberg reconoce que los factores implicados en la etiología de la homosexualidad son numerosos: la fijación a la madre, la identificación con la madre, la tendencia a un tipo narcisista de elección de objeto (incluida la sobrevaloración del genital masculino), y el miedo al padre o, en otras palabras, la angustia de castración. Por último, y quizás lo más fundamental, la homosexualidad se ve favorecida por una actitud pasivo-anal hacia el objeto de su amor.

Rosenfeld contribuye a la discusión acerca de las relaciones entre paranoia y homosexualidad. Gracias a sus experiencias con pacientes paranoides coincide estrechamente con la opinión de Melanie Klein acerca de la fijación del paranoico a una fase oral precoz (posición paranoide) y cree que la homosexualidad del paranoico tiene una naturaleza secundaria y defensiva. La fijación a este nivel inicial de desarrollo puede contribuir considerablemente al desarrollo de la homosexualidad posterior. En el análisis de un paciente psicótico, la homosexualidad manifiesta estaba al servicio de un mecanismo de proyección defensiva que tenía rasgos claramente maníacos. En otro paciente neurótico, una parte de la homosexualidad era causada por sus intentos de apaciguar figuras persecutorias externas a través del coito anal pasivo y por la necesidad de probar a sí mismo, a través de una felación, la destructividad de sus impulsos orales. Además, «the manifest homosexuality was here used as a defence against depression» (Rosenfeld 1949, p. 41). Según él, la homosexualidad está relacionada con la idealización de la figura del 
padre bueno, que se utiliza para negar la existencia de un perseguidor. La homosexualidad puede ser utilizada por el sistema de defensa maníaco. Para Rosenfeld, incluso en la homosexualidad manifiesta de un sujeto no psicótico, se encuentran con frecuencia graves ansiedades paranoides ocultas. El origen del mecanismo de identificación proyectiva se remonta a los primeros impulsos infantiles que encierran el Self dentro de la madre. La fijación a este nivel temprano, que ha sido llamada por Melanie Klein la posición paranoide, puede ser responsable de la combinación frecuente de paranoia y homosexualidad.

La bisexualidad era un concepto fundamental en el pensamiento de Freud. En un desarrollo normal, los componentes homosexuales son sublimados. Sin embargo, la existencia de una homosexualidad manifiesta implica, para Freud, que existe una tendencia profunda a la bisexualidad. Muchos de los argumentos a favor o en contra de la homosexualidad se derivan del concepto de bisexualidad psíquica. Wilhelm Stekel pensaba que la bisexualidad es la condición natural del hombre. La monosexualidad, según él, es innatural. El heterosexual puro está condenado a la neurosis: «There are no monosexual persons! The heterosexual period stretches far into puberty. All persons are bisexual. But persons repress either the homosexual or the heterosexual components on account of certain motives or because they are compelled by particular circumstances and consequently act as if they were monosexual.» (Stekel 1922, p. 27). Douglas Bryan subrayó la importancia de la bisexualidad en la explicación de la sexualidad masculina y femenina. Creía que hay una resistencia a utilizar este concepto incluso entre los analistas.

Sandor Rado fue un exponente del desarrollo homofóbico post-freudiano. Luchó contra el concepto de bisexualidad en un famoso artículo (Rado, 1940). El trabajo de Rado debe situarse en un contexto más amplio de cambio del énfasis analítico clásico sobre el complejo de Edipo. A partir de la primera parte de la década de los años treinta, se prestó una atención considerable a la fase oral del desarrollo infantil. Esta fase, descrita por Freud, y estudiada detalladamente por Melanie Klein, se convirtió poco a poco en el lugar del desenlace del drama de la identificación sexual. A pesar de la insistencia de Freud sobre las fases fálicas y genitales, sus teorías sobre la sexualidad se dirigían hacia el estudio de las condiciones infantiles primitivas. Por ejemplo, la oposición entre masculinidad y feminidad era central para el proceso de identificación y elección de objeto sexual; sin embargo, no sabemos por qué la masculinidad se confunde con la actividad y la feminidad con la pasividad. En otras palabras, la polaridad preedípica de actividad-pasividad precede a la de masculinidad-feminidad. Al repudiar la bisexualidad y la homosexualidad constitucional, Rado fundaba la aproximación a la homosexualidad sobre factores psicosociales. 
Poe niega la validez de la teoría freudiana de la bisexualidad y describe la cura de un paciente homosexual usando la teoría de adaptativa de Rado. El tratamiento, según el autor, tuvo un éxito positivo con tan sólo ocho meses de seguimiento. Era un hombre de 39 años de edad que había sido un homosexual de tipo anal desde los siete años. A través de sesenta y cinco sesiones de psicoterapia psicodinámica, utilizando un punto de vista adaptativo de la conducta sexual, Poe logró cambiar la orientación sexual de este paciente. La base de la cura, según Poe, era un «attempt to initiate emotional forces which will banish fears, thus releasing inhibitions and allowing the restoration of healthy function.» (Poe 1952, p.27)

Gustav Bychowski delineó las características del yo en el homosexual. Encontró mecanismos de defensa primitivos como la escisión, la introyección, la negación y la retirada narcisista, considerándolos de vital importancia en la génesis de la homosexualidad. El yo se debilita en estos casos debido a la necesidad de mantener varias identificaciones que se han vuelto disociadas unas de otras, de manera que la libido no está disponible para la investidura de objeto. La liberación repentina de los impulsos agresivos libidinales indiferenciados conduce a breves intentos de establecer contacto con los objetos, porque el yo mal estructurado del homosexual no es capaz de unir las energías instintivas del proceso primario.

Gustav Bychowski escribió acerca del yo y las relaciones de objeto de los homosexuales. En su opinión, en la literatura analítica no se prestó tanta atención a la personalidad total y al yo del homosexual. Bychowski ha dedicado estudios especiales a las afinidades entre la esquizofrenia y la homosexualidad. Encontró algunas analogías en sus estructuras psíquicas, especialmente el infantilismo en la organización de la libido y ciertas características primitivas del yo. Añadió que hay que mantener cierta cautela en la caracterización del yo del homosexual, señalando que parece que hay ciertos individuos bien integrados y productivos que, aunque homosexuales, parecen ser capaces de largas relaciones de amor en lugar de perseguir satisfacciones momentáneas. Para Bychowski, los límites del yo del homosexual no son firmes y es posible que haya identificaciones efímeras. "The homosexual's ego boundaries lack fixity; this makes fleeting identifications possible; that is, temporary fusion with another person or merely the taking over some of that person's characteristics» (Bychowski 1961, p. 256).

Según Bychowski, ya que el yo tiene una estructura arcaica, es muy vulnerable a los efectos de la estimulación de la libido. La renuncia de gratificaciones primitivas con objetos originales se hace imposible. Freud ya había mencionado la incapacidad del homosexual para unir energías instintivas originales y transformarlas en energías disponibles para el 
proceso secundario. El yo primitivo utiliza el mecanismo de la incorporación en un alto grado; los objetos originales, nunca abandonados, se incorporan al yo y siguen siendo los prototipos para una futura elección de objeto. Esto contribuye a una escisión y el yo se llena, por así decirlo, de contenidos contradictorios. Para agravar la situación, la debilidad del yo inmaduro no permite una síntesis de las actitudes conflictivas originales. Aquí la analogía con el yo psicótico o pre-psicótico es evidente.

\section{El triunfo de la clínica: el homosexual perverso}

En los años cincuenta y sesenta el número de publicaciones sobre la homosexualidad aumentó. Este período se caracterizó por un tono cada vez más moralista. La característica más llamativa de las teorías sobre la homosexualidad fue el intento de negar la base constitucional de las desviaciones sexuales y, más en general, de minimizar la importancia de la sexualidad en la motivación humana. De gran importancia teórica fue la negación de que otros factores de la sexualidad eran de naturaleza constitucional. El complejo de Edipo negativo, por ejemplo, ya no era visto por algunos analistas como una etapa primaria del desarrollo psicosexual, sino, más bien, como un mecanismo de defensa secundario contra la anterior variedad positiva. Para algunos analistas, el narcisismo no era una dotación constitucional sino una defensa contra la agresividad hacia el objeto libidinal. Y poco después $\mathrm{H}$. Kohut propondrá una línea de desarrollo narcisista independiente de la libidinal, cuyas implicaciones merecen un estudio aparte, en otro trabajo.

En este periodo, se piensa que los conflictos, en lugar de ser intrapsíquicos e instintivos, son de tipo interpersonal. Se minimiza la importancia de los procesos puramente intrapsíquicos en la determinación de la elección de objeto homosexual y se buscan las causas en eventos particulares en el entorno psicológico del niño.

Stephen Mitchell nos recuerda que Freud pensaba que la orientación sexual era, en gran medida, constitucional; en muchos casos, la homosexualidad no era principalmente defensiva, por lo tanto, pensaba Freud que cambiar la orientación sexual no era un objetivo adecuado en el tratamiento analítico. Una de las pocas ideas de Freud que el psicoanálisis estadounidense desatendió completamente (además de su apoyo a los analistas legos) era su actitud hacia la orientación sexual. «As psychoanalysis was accepted by American society, with its prominent homophobic currents, a different kind of biological determinism was established. In the 1950 s and 1960s, the position that dominated the American psychoanalytic literature was that everyone is constitutionally heterosexual and that homosexuality is a pathological, defensive, phobic retreat from castration fears. In this directive-suggestive approach, analytic clinicians were urged to insist that homosexual 
patients renounce their sexual orientation and actively direct the process of conversion into what the analyst considered the "good", that is heterosexual life» (Mitchell 1997, p. 254)

Charles Socarides pone en evidencia la conexión entre homosexualidad y esquizofrenia: «In clinical experience, nevertheless, the connection between homosexuality and both paranoid schizophrenia and paranoia is striking in a great number of patients and it occurs with considerable regularity.» (Socarides 1978, p.60).

Para Edmund Bergler, el homosexual es una persona que tiene una fijación a la fase oral y que predominantemente utiliza la homosexualidad como mecanismo de defensa inconsciente para escapar de una relación de apego masoquista a la madre pre-edípica. El homosexual, según Bergler, busca el pene de otro hombre como reduplicación de su propio pene que se ha convertido en una compensación narcisista del seno que le decepcionó. El psicoanálisis, para Bergler, siempre ha considerado el homosexual como un fugitivo lleno de miedo que huye de ideas erróneas que inconscientemente construye en torno a la mujer. El homosexual masculino ha tenido, como todo ser humano, una primera experiencia específica con su madre. Esta experiencia emocional muy real con una mujer deja sus marcas. Cuando más tarde elige a otro hombre como objeto sexual, lo hace en una elaboración neurótica de esa primera experiencia.

La perversión homosexual se caracteriza, según Bergler, por la aceptación consciente de la gratificación sexual derivada de una relación con un objeto del mismo sexo. Los homosexuales pretenden imitar la relación marido-mujer. Por lo tanto, en la variedad pasiva, imitan a las mujeres, en la forma de vestir, en los movimientos, en la manera de hablar y en el uso de perfumes y cosméticos. De aquí se deriva la idea errónea que todo hombre afeminado es homosexual. Nada más lejos de los hechos clínicos. Al aceptar este camuflaje superficial, un observador ingenuo cae en el juego inconsciente de los homosexuales. Todo homosexual es un ejemplo de masoquismo. Los homosexuales, para Bergler, son personas enfermas que necesitan ayuda.

«Homosexuals are essentially disagreeable people, regardless of their pleasant or unpleasant outward manner. True, they are not responsible for their unconscious conflicts. However, these conflicts sap so much of their inner energy that the shell is a mixture of superciliousness, fake aggression, and whimpering. Like all psychic masochists, they are subservient when confronted with a stronger person, merciless when in power, unscrupulous about trampling on a weaker person. The only language their unconscious understands is brute force. What is most discouraging, you seldom find an intact ego (what is popularly called a correct person) among them.» (Bergler 1956, p. 29) 
Según Bergler, lo que es específicamente característico del homosexual es el hecho de que la estructura narcisista acentúa el mecanismo de la oralidad a la enésima potencia. Según él, la arrogancia verdaderamente megalómana de los homosexuales es única. Debido precisamente a su subestructura narcisista, el trauma causado por la incapacidad de mantener la fantasía de omnipotencia infantil hace que los niños se conviertan en homosexuales. Se recuperan sólo parcialmente de la derrota del destete y sólo a través de una recompensa narcisista. Es aquí donde la reduplicación de sus propios mecanismos de defensa entra en juego.

Para Bychowski, es evidente que el comportamiento homosexual no está sólo asociado a menudo con otras perversiones, sino que, en sí mismo, es el resultado de graves dificultades en el desarrollo de la personalidad.

Muy a menudo se trata de una manifestación de ansiedad profunda, de miedo a la castración, de sensación de debilidad del yo que busca las fuentes de «replenishment» en el contacto con otros varones. La capacidad de amar está a menudo profundamente perturbada; el sentido de realidad puede no ser suficientemente desarrollado, de manera que hay un predominio de retirada esquizoide y narcisismo inusual. Un amplio conjunto de compensaciones reactivas se suma a la caracterología homosexual. Bychowski subraya las conexiones entre la psicosis y la homosexualidad: el yo de los homosexuales y de los psicóticos presenta el mismo tipo de debilidad.

Irving Bieber publicó en 1962 Homosexuality, A Psychoanalytic Study, uno de los estudios más extensos sobre la homosexualidad. Podría considerarse la respuesta psicoanalítica al informe Kinsey. Es un estudio colectivo de 106 homosexuales masculinos comparados con 100 pacientes heterosexuales. Los terapeutas que participaron en este estudio muestran dos orientaciones teóricas principales: el 70 por ciento eran freudianos y el 30 por ciento eran culturalistas ${ }^{2}$. Los freudianos veían el complejo de Edipo como una parte integral del desarrollo psicosexual que opera en todas las culturas; los culturalistas veían el complejo de Edipo como algo que ocurre sólo en una matriz familiar altamente psicopatológica y por lo general asociada a la esquizofrenia. La investigación se basa en un cuestionario con 450 preguntas sobre el desarrollo y las relaciones de objeto psicosexuales de los pacientes, su historial médico, su entorno sociocultural, su situación económica, el carácter de sus padres, la naturaleza de sus actividades sexuales, sus fantasías sexuales, sus miedos, su psicopatología, la motivación para el tratamiento, y los resultados del mismo. En sólo

\footnotetext{
${ }^{2}$ Las implicaciones de las propuestas sobre el papel de la elección homosexual en el desarrollo de la personalidad normal fueron uno de los temas más destacados de las contribuciones de H.S. Sullivan sobre la adolescencia, las cuales merecen un trabajo de revisión aparte.
} expresa. Este material es para uso científico y profesional exclusivamente y puede contener información clínica sensible. Los editores no se responsabilizan de los contenidos de los autores. Dirigir las consultas sobre derechos y autorizaciones a ceir@psicoterapiarelacional.es 
nueve de las 450 preguntas hay diferencias estadísticamente significativas en las respuestas de los freudianos frente a los terapeutas culturalistas. Siete de estas nueve preguntas tratan de factores sexuales. Los culturalistas parecen subestimar los factores sexuales. El primer aspecto investigado en este trabajo es la relación madre-hijo de hombres homosexuales en comparación con los heterosexuales. De 70 preguntas que tratan de la relación madre-hijo, 27 resultan lo suficientemente relevantes como para indicar diferencias estadísticamente válidas en la relación madre-hijo entre el grupo homosexual y el grupo heterosexual. Según el estudio, el setenta y tres por ciento de las madres de los homosexuales tiene una relación extraordinariamente íntima con sus hijos, con frecuencia combinada con un comportamiento seductor y un control excesivo.

Podemos leer el trabajo de Bieber y colaboradores como una respuesta psicoanalítica al informe Kinsey que no considera la homosexualidad como una condición patológica sino como una variante no normativa de la sexualidad.

Probablemente, el autor más representativo de la creación en un estereotipo psicoanalítico del homosexual es el ya citado Charles Socarides.

El primer artículo sobre la homosexualidad lleva la fecha de 1960 y el último trabajo sobre las perversiones sexuales es de 2002. Socarides es importante por varias razones. En primer lugar, representa el psicoanálisis ortodoxo y se esfuerza de enmarcar sus teorías dentro de la historia de psicoanálisis. Sus libros empiezan siempre con una historia de las ideas psicoanalíticas acerca de la homosexualidad con la intención de mostrar que sus conclusiones son una continuación de esta línea de investigación.

Hace suyas tanto las teorías edípicas como las teorías pregenitales. En segundo lugar, sus posiciones no han cambiado a lo largo de cuarenta años, a pesar de que a partir de los años ochenta tiene lugar en el movimiento psicoanalítico un cambio de actitud hacia la homosexualidad. Muchos autores analíticos responsables y atentos a los hechos clínicos rompen la conexión entre homosexualidad y psicopatología.

En el 1990 las sociedades psicoanalíticas internacionales aceptan candidatos abiertamente homosexuales. Socarides, a lo largo de toda su vida científica, considera la homosexualidad como un fenómeno clínico patológico que tiene una etiología muy variada e incluso una posibilidad de tratamiento.

Según Socarides, la teoría del origen pre-edípico de la homosexualidad tiene tres aspectos. El primero es la presencia de una fijación durante los tres primeros años de vida. El homosexual, según Socarides, ha sido incapaz de atravesar con éxito la separación de la madre y empezar el proceso de individuación. El segundo es la utilización del mecanismo 
de las perversiones sexuales descrito por Hanns Sachs en el 1923. El tercero es la teoría de Spitz de la sincronicidad que debe existir entre el cumplimiento del proceso maduración y su contraparte de maduración psicológica.

Esta teoría sostiene que todos los homosexuales preedípicos han sido incapaces de pasar de la unidad materno-infantil a la individuación.

Como resultado, existe, en estas personas, una fijación y una tendencia concomitante a la regresión. Esto se manifiesta como una amenaza de aniquilación, una pérdida de los límites del yo, y un sentido de fragmentación.

Spitz piensa que, cuando no puede tener lugar un desarrollo psicológico adecuado a una edad, es difícil, si no imposible, para el individuo adquirirlo en una etapa posterior. Por ejemplo, si un niño no tiene el deseo de caminar cuando la maduración de la inervación de la parte inferior del cuerpo le permite andar, el niño es incapaz de levantarse o caminar sin apoyo. Más tarde, como consecuencia de un trauma, puede regresar a la etapa en la que no podía ni caminar ni pararse ni sentarse.

Socarides usa las observaciones de Spitz para aplicarlas al problema del desarrollo de la homosexualidad. Según Socarides, el homosexual no ha podido separarse de la madre en la etapa adecuada de desarrollo. Como resultado, sigue existiendo un punto de fijación crónica, a pesar de haber pasado a través de otras fases de maduración con cierto éxito. En estas posiciones de maduración, se han formado estructuras desviadas de compensación en un intento de reparar la deficiencia infantil. Estas estructuras están íntimamente relacionadas con los problemas de identidad, las fronteras defectuosas del yo, las ansiedades introyectivas y proyectivas, los temores de fusión y los trastornos en la capacidad de formar relaciones de objeto.

Socarides es muy explícito en la vinculación de la homosexualidad preedípica a una condición psicopatológica grave: la homosexualidad preedípica es una condición intermedia entre la psicosis, los trastornos límite de la personalidad y las neurosis. Para distinguir una fijación edípica de una fijación preedípica, Socarides identifica algunos factores. En la forma preedípica encontramos: una identificación primaria con la madre acompañada con una confusión de género, una intensa ansiedad generada por intentar separarse de la madre, una actitud infantil, trastornos en los límites del yo y en la imagen del cuerpo, presencia de complejos orales y agresivos de incorporación que llevan a ansiedades orales, presencia de objetos persecutorios, miedos de envenenamiento y temor a ser engullido. 
Socarides no ve en la homosexualidad ningún potencial de desarrollo humano. No existe un amor homosexual maduro sino sólo narcisista y destructivo.

Para Franco Fornari, la homosexualidad es causada tanto por una identificación introyectiva con la madre como por una identificación proyectiva con el objeto. El aspecto más relevante de la relación homosexual es el narcisismo. Fornari propone el mito de Narciso para ejemplificar la estructura de la homosexualidad. Narciso rechaza a las mujeres, se enamora de su imagen y por eso muere. En este mito, están relacionados el rechazo del objeto genital, el amor de sí mismo y la muerte. Según Fornari, la homosexualidad niega, a través de la identificación introyectiva, la dependencia del objeto. El homosexual niega la necesidad de la madre e intenta negar el sufrimiento por su inevitable pérdida. Fornari, a diferencia de muchos analistas que no habían aceptado el concepto de instinto de muerte freudiano, formula las siguientes ecuaciones:

homosexualidad $=$ narcisismo $=$ rechazo realidad $=$ rechazo vida $=$ instinto de muerte

\section{Ganimedes entre los dioses: el fin de la etiología}

El debate sobre la etiología de la homosexualidad tuvo su apogeo en los años 50 y 60 . A partir de los años 70, algunos autores empiezan a cuestionar el modelo patológico y salen de su aislamiento analítico incorporando al psicoanálisis nuevas aproximaciones y una nueva sensibilidad. A finales de los años sesenta empiezan a modificarse las condiciones sociales de los homosexuales. Muchos se organizan en colectivos y reivindican sus derechos.

Se hacen cada vez más visibles homosexuales que no presentan psicopatologías. La psiquiatría, una disciplina que, por lo menos en Estados Unidos, tenía fuertes vínculos con el psicoanálisis, desclasifica en 1973 la homosexualidad como perversión y adopta formalmente esta decisión con la publicación del DMS-III en el 1980. En 1975, la American Psychological Association se pronuncia en contra de todo tipo de discriminación hacia los homosexuales.

En 1990, la Organización Mundial de la Salud elimina la homosexualidad de su lista de enfermedades psiquiátricas. En este periodo, también se multiplican los estudios sobre las sexualidades desde una perspectiva antropológica y cultural. Dentro el psicoanálisis hay una difusión de los modelos psicoanalíticos relacionales que relativizan la centralidad de la teoría psicosexual clásica.

Como hemos dicho, a partir de los años ochenta muchas sociedades psicoanalíticas empezaron a aceptar candidatos homosexuales. Recordemos que Freud, muchos años 
antes, ya se había expresado favorablemente acerca de aceptar candidatos analistas homosexuales. Autores destacados (p.e. Stephen Mitchell) ya sostienen que la homosexualidad es una expresión de la sexualidad humana no patológica. Entre los primeros analistas que deciden hacer outing, encontramos a Richard Isay y Ralph Roughton, que durante años elaboran una revisión crítica de las teorías psicoanalíticas tradicionales sobre la homosexualidad. Lentamente emerge la idea de que la homosexualidad como tal no es una enfermedad. Existen homosexuales con una personalidad integrada, capaces de relaciones objetales y con un yo estable.

En 1991, la American Psychoanalytic Association (APsaA) aprueba un documento en el que deplora toda discriminación pública y privada contra las personas homosexuales, e invita a sus instituciones psicoanalíticas a seleccionar sus candidatos basándose no en su orientación sexual, sino sólo en su interés por el psicoanálisis, talento, preparación cultural, integridad y analizabilidad psicológica. Un año más tarde, el documento es integrado con una enmienda en la que se hace hincapié en que los candidatos homosexuales pueden acceder a las posiciones de analista didacta y supervisor.

En 2005, la American Psychiatric Association aprueba un documento que apoya las uniones entre personas del mismo sexo.

El cambio de los valores culturales ejerce un profundo influjo sobre las teorías analíticas que ahora retratan la homosexualidad como una variante normal de la sexualidad humana. La moral sexual se ha hecho más tolerante desde los años sesenta, de manera que han surgido modelos dinámicos no patológicos. El analista y el paciente, por ejemplo, simplemente asumen que la homosexualidad es intrínseca y normal en el paciente. Como el origen de la homosexualidad se atribuye a factores totalmente desconocidos, la etiología de la homosexualidad ya no es considerada como un tema de investigación analítica. Incluso en los casos en que el analista y el paciente creen que la homosexualidad es un producto de conflictos, tal resultado no se presume inferior a una orientación heterosexual que también es producto de otro tipo de conflictos. Desde esta perspectiva, el analista y el paciente se eximen de averiguar lo que ha impedido el desarrollo heterosexual del paciente. Richard Friedman sintetiza muy bien este momento de pasaje de una teoría analítica estancada en sus posiciones etiopatológicas a una teoría psicosexual más abierta y tolerante.

A partir de los años setenta nacieron muchos centros de estudio destinados explícitamente a la profundización y deconstrucción del concepto de género relacionado. Anteriormente se hacía hincapié en un modelo dicotómico de la naturaleza humana donde las categorías de masculino-femenino, activo-pasivo, heterosexual-homosexual, sexualidad y orientación sexual se usaban sin un esfuerzo crítico de definición. La contribución de los 
estudios de género ha sido importante para reconocer las estrategias culturales que se esconden detrás de los presuntos hechos naturales. Para la mayoría de estos estudiosos, el género y la sexualidad han de entenderse como elementos flexibles y como categorías que organizan la experiencia psicológica y social (Dimen y Goldner, 2002).

Con el desarrollo del psicoanálisis relacional, la visión patológica de la homosexualidad empieza a cuestionarse. Los analistas relacionales entienden que las fantasías y las prácticas sexuales ayudan a dar forma a las matrices interpersonales a través de las cuales se desarrollan las personas. El foco del psicoanálisis ya no es la dinámica pulsional del individuo, sino la calidad de sus relaciones. Ya hemos citado que Stephen Mitchell fue una de las primeras voces carismáticas del psicoanálisis en considerar la homosexualidad una expresión de la sexualidad humana no necesariamente patológica e invocar nuevos paradigmas para la comprensión de los aspectos dinámicos del desarrollo de las elecciones de objeto.

La posición del psicoanálisis relacional acerca de la sexualidad en general es diferente de la posición freudiana clásica. La sexualidad, para Mitchell, es una respuesta dentro de una matriz relacional, es una manera que el individuo tiene de relacionarse con otros individuos. Si, para Freud, el impulso sexual crea la relación, para Mitchell, la necesidad de relación vehicula la sexualidad.

El simple esquema de la teoría de la fijación libidinal de la neurosis, en la que el funcionamiento sexual es la pieza central de la personalidad, que determina el nivel de integración y de desarrollo, fue sustituido por una visión más compleja del funcionamiento de la personalidad en el que el desarrollo del yo y la riqueza de las relaciones de objeto pueden o no estar relacionadas con el funcionamiento sexual.

Mitchell recuerda que el concepto de sobredeterminación fue introducido por Freud en 1901, en relación a la comprensión de las imágenes del sueño. Freud sostiene que la imagen de un sueño específico no se limita a tener un significado, o una fuente psicodinámica, sino que tiende a ser una construcción compleja vinculada a muchas ideas, deseos y recuerdos. No sólo las imágenes de los sueños, sino todos los componentes de la conducta y de la experiencia son sobredeterminados y expresan significados diferentes. Este principio, sin embargo, tiende a perderse cuando se aplica a la homosexualidad. Se asume que, si el comportamiento homosexual implica, por ejemplo, una defensa activa contra el miedo a la castración, o es una expresión de deseos simbióticos, entonces éstos se transforman en las únicas motivaciones que explican el comportamiento homosexual. No se toma en cuenta la posibilidad de otros significados y motivos de este comportamiento, incluyendo sentimientos y deseos de intimidad en otros niveles. Mitchell afirma que el 
comportamiento homosexual no es sólo expresión de conflictos psicodinámicos, «the behavior has meanings, apart from the psychodynamic conflicts, that might include the adaptive functioning of the ego, mastery of the environment, satisfaction of other needs, varieties of interpersonal contacts, and so forth.»(Mitchell 1978, p 9).

Otros autores han cuestionado la teoría sexual freudiana clásica. No se puede vincular el desarrollo libidinal con la maduración de la personalidad.

Judd Marmor, psiquiatra con formación psicoanalítica, tuvo una importante influencia no sólo entre los psiquiatras sino también en el ámbito psicoanalítico al considerar la homosexualidad una variante de la sexualidad humana. Como vicepresidente de la Asociación Americana de Psiquiatría, fue franco al decir que los criterios que normalmente se aplican para clasificar una enfermedad mental no se aplicaban a la homosexualidad. Marmor piensa que incluso desde una perspectiva ética, la etiología de la homosexualidad no debería ser de ninguna importancia. La homosexualidad puede ser innata, adquirida o elegida conscientemente, o cualquier combinación de estos casos; de todos modos, el imperativo ético más alto en una sociedad moderna es que los homosexuales no deben ser tratados de forma diferente a cualquier otro grupo religioso, étnico o racial. Para Marmor, la cuestión fundamental planteada por la situación nosológica de la homosexualidad no era ni clínica ni semántica, sino moral. Ya que los homosexuales son capaces de adaptarse con éxito en la sociedad, no se puede justificar la clasificación de la homosexualidad como una enfermedad. Marmor destaca la importancia de la tolerancia en el comportamiento sexual y señala que la clasificación psiquiátrica de la homosexualidad como una enfermedad mental ha tendido a justificar la intervención agresiva de la sociedad en la vida de los individuos (Marmor, 1972).

Los años 90 vieron un crecimiento de las publicaciones de analistas homosexuales que plantean nuevos problemas y plantean preguntas antes inexploradas. Se volvió a escribir la historia y la técnica psicoanalíticas del tratamiento de pacientes homosexuales, se postularon modelos normales de desarrollo para los niños que se convierten en homosexuales, se cuestionaron los conceptos analíticos tradicionales de masculinidad y feminidad, se modificó la técnica psicoanalítica para intervenir con pacientes con SIDA, y se arrojó luz sobre importantes contribuciones previamente invisibles.

El primero en salir del armario fue Richard Isay que, desde finales de los años ochenta, publica trabajos acerca de la homosexualidad. Este autor hace hincapié en los factores constitucionales. De esta manera, tanto el analista como el paciente se concentran no en la búsqueda de las causas psicodinámicas de la homosexualidad sino en la resolución de conflictos actuales que no tienen en cuenta la orientación sexual. Isay, al proponer que la 
homosexualidad predominante o exclusiva es de origen constitucional, concluye que es una orientación sexual fija e irreversible y que no se relaciona a ninguna forma de psicopatología. Isay basó sus conclusiones en el trabajo analítico con hombres gay bien integrados, altamente funcionales, que previamente no habían estado bien representados en la literatura analítica. Junto a un número creciente de otros clínicos analíticos, ha argumentado que los modelos psicoanalíticos de orientación sexual producidos en los años cincuenta y sesenta no son válidos. Según Isay, los niños homosexuales desarrollan fantasías eróticas hacia el padre a partir de la edad de cuatro o cinco años.

Para Isay, la persona homosexual tiene en su infancia una constelación edípica específica: un desarrollo de las fantasías de amor hacia su padre y no hacia su madre. En su opinión, la terapia analítica debe ayudar al paciente a aceptar su identidad homosexual resolviendo su homofobia inconsciente. A pesar del impacto revolucionario de sus teorías, Isay todavía propone un modelo de terapia orientada, sobre la base de una hipótesis biogenética de la homosexualidad. Isay desarrolla un modelo alternativo que, sin embargo, sigue dando importancia a los factores constitucionales en los mismos años en que las teorías relacionales estaban tratando de liberar la sexualidad de la dominación de la teoría psicosexual.

Isay informa también sobre fantasías homosexuales de hombres heterosexuales hasta incluir transferencias eróticas. En nuestra sociedad, lo que es femenino ha simbolizado la pasividad y la sumisión, y lo que es masculino ha representado la actividad y el poder. A veces, el deseo de ser como una mujer puede actuar como defensa contra el riesgo de que algunos hombres se sientan conectados a su asertividad y competitividad. De esta manera, el deseo de feminidad toma la forma de lo que, en nuestra sociedad, los heterosexuales experimentan como fantasías homosexuales. La expresión del deseo de ser como una mujer toma la forma de fantasías homosexuales, y, por tanto, estas fantasías expresan la creencia de que los homosexuales son por naturaleza pasivos y sumisos. En este aspecto, Isay está de acuerdo con Ovesey, que denominó las conductas y las fantasías homosexuales defensivas en los heterosexuales con el nombre de pseudo-homosexualidad.

La homosexualidad defensiva es más común en aquellos heterosexuales que perciben a sus padres como personas fuertes, autoritarias y aterradoras y a sus madres débiles, dominadas y humilladas por sus maridos. Esta imagen, que a menudo tiene base en la realidad, es utilizada por los niños heterosexuales para consolidar su deseo edípico de aliarse con la madre para salvarla del padre.

Cita el caso de Bob, que tiene muchas fantasías y sueños homosexuales, incluido besar al analista y ser penetrado por él. Bob también confiesa que ha tenido una erección durante 
una sesión. Isay describe a Bob como un hombre que teme la castración y el rechazo por parte del analista y, por lo tanto, siente la necesidad de someterse a él de esta manera femenina. En el momento más intenso de estas fantasías homoeróticas de Bob hacia el analista, empieza a tener relaciones heterosexuales muy satisfactorias fuera del tratamiento. Según Isay, un verdadero homosexual habría desarrollado una homosexualidad manifiesta en este momento del tratamiento, a diferencia de Bob, que hizo todo lo contrario. De hecho, Isay afirma que el comportamiento homosexual es egosintónico para los verdaderos homosexuales, si bien es egodistónico para pseudohomosexuales como Bob. De esta manera, Isay resuelve casos de homosexualidad secundaria porque, en estos casos, la base patológica del comportamiento no es la homosexualidad en sí sino el miedo a la castración y al rechazo.

Ralph Roughton es otro psicoanalista homosexual que trabaja dentro de la Asociación Psicoanalítica Internacional (IPA). Roughton se opone a la misma idea de etiología de la homosexualidad. El psicoanálisis no sabe explicar la orientación sexual; y Freud consideraba inexplicables tanto la homosexualidad como la heterosexualidad. Según Roughton, la búsqueda de las causas de la homosexualidad puede esconder una homofobia interiorizada aunque el analista opere con las mejores intenciones y sin prejuicios. Lo importante es considerar la homosexualidad una variante normal de la sexualidad de manera que la orientación sexual y la psicopatología sean variables completamente independientes. Al resumir su punto de vista clínico, hay que enfatizar los siguientes puntos: no sabemos mucho sobre el origen y el desarrollo de la orientación sexual y es más seguro asumir que la orientación sexual y la salud mental son variables independientes. Podríamos hablar de una perversión o narcisismo en una persona homosexual, en lugar de considerar la elección de objeto homosexual basada en dicha patología (Roughton, 1993), la expectativa de descubrir la etiología patológica de la homosexualidad distorsiona inevitablemente el proceso analítico, la calidad de las relaciones y la integración del placer y de la identidad son mejores indicadores del éxito del análisis que el género de las parejas sexuales, una identidad positiva como hombre homosexual es tan deseable como una identidad heterosexual, hasta los analistas más neutrales se ven, sin saberlo, guiados por la teoría etiológica clásica, tienen prejuicios culturales no reconocidos y actitudes contratransferenciales negativas. El autoanálisis es un requisito previo para trabajar con los homosexuales.

Para Roughton, un proceso analítico que se centra en el descubrimiento de la supuesta etiología patológica de la homosexualidad inevitablemente distorsiona el proceso, reduciendo cada conflicto que surge a la supuesta patología. 
Roughton también recuerda que, a pesar de los parecidos entre el paciente heterosexual y el paciente homosexual, hay que tener presentes las diferencias: en el paciente homosexual muy a menudo se encuentra la homofobia interiorizada, el sentido de culpa y la interiorización del odio social.

Es interesante analizar la evolución del pensamiento de Kernberg acerca de la homosexualidad. En 1975, Kernberg pensaba que la homosexualidad era una enfermedad: la colocaba dentro de un continuo patológico de relaciones objetales interiorizadas. Las menos graves, de naturaleza edípica, se podían tratar más fácilmente que las de tipo narcisista. Se puede notar ya un cambio en 1992 en la descripción de la condición patológica de la homosexualidad. Para Kernberg, existe la posibilidad de una homosexualidad no patológica, aunque rara. En 2002, Kernberg vuelve a considerar el tema de la patología de la homosexualidad. Llega a la conclusión de que no existe una única homosexualidad sino un abanico de orientaciones homosexuales que reflejan factores etiológicos distintos. Así como la heterosexualidad, la homosexualidad presenta todo el espectro clínico que va desde la patología grave hasta la salud.

Kernberg reconoce que las características más importantes y dominantes de la identidad de género masculino y femenino se construyen culturalmente. Acerca de la cuestión del tratamiento de los homosexuales, Kernberg es muy claro: el analista tiene que ser lo más neutral posible y tiene que consolidar la orientación sexual del paciente.

El psicoanálisis de los últimos treinta años parece haber asimilado una nueva visión de la homosexualidad también porque ha incorporado una nueva visión de la sexualidad. Una visión polifacética y deconstruida. Se pueden distinguir varios niveles de la sexualidad humana (Argentieri, 2010). Un primer nivel biológico y anatómico; un segundo nivel que está en relación con el género, es decir, el sentido psicológico de pertenencia al género masculino o femenino; un tercer nivel que está en relación con las vicisitudes pulsionales y que conduce al comportamiento sexual propiamente dicho; un cuarto nivel que se refiere a los roles y a las funciones sólo secundariamente sexualizadas en su contexto socio-cultural; un nivel metafórico en el que se habla de masculino o femenino como extensión analógica, poética y evocadora de la palabra, como compleja duplicidad dialéctica de la misma realidad humana. Estos niveles nunca están mutuamente armonizados e integrados.

La identidad sexual atraviesa todos esos niveles y se configura dinámicamente en el sujeto y en la cultura de la sociedad. En este siglo XXI, el psicoanálisis tendrá que ocuparse de la homosexualidad de manera distinta. Ya no interesan las cuestiones relativas a su etiología y a su estatuto patológico. La homosexualidad es una de tantas declinaciones de la sexualidad a través de las cuales el ser humano se proyecta en el mundo con la esperanza 
de realizar una experiencia vital auténtica y completa. La tarea del psicoanálisis no consiste en ofrecer clasificaciones de las desviaciones sexuales y métodos para su eventual tratamiento, sino en atreverse en proponer modelos existenciales que alcancen esa autenticidad. Hace un siglo, Freud afirmaba que tanto la homosexualidad como la heterosexualidad son un misterio y que el hombre sano es el hombre que sabe amar y sabe trabajar. Hoy añadimos que también la sexualidad en sí es un misterio, porque es un fenómeno irreductible, como es incomprensible e irreductible la tensión del hombre hacia el amor.

\section{REFERENCIAS}

Argentieri, S. (2010). A qualcuno piace uguale, Einaudi.

Bergler, E. (1956). Homosexuality: Disease or Way of Life?, Hill and Wang.

Bychowski, G. (1961). The Ego and the Object of the Homosexual, The International Journal of Psychoanalysis, vol. 42, pp. 255-259.

Brill, A. The conception of homosexuality, Journal of the American Medical Association, vol. 61, pp. 335-340, 1913.

Dimen, M y Goldner, G. (2002). Gender in Psychoanalytic Space, Other Press

Krafft-Ebing, R. (1890). Lehrbuch der Psychiatrie auf klinishe Grundlage, Stuttgart, Enke. Se cita la traducción inglesa Textbook of Insanity, Filadelfia, G.A. Davies, 1904.

Ferenczi, S. (1909). Nuevas Observaciones sobre la Homosexualidad. Se cita la traducción española en Obras completas II, RBA, 2006.

Ferenczi, S. (1914). Omoerotismo: nosología de la homosexualidad masculina. Se cita la traducción española en Obras completas I, RBA, 2006.

Freud, S. (1905). Tres ensayos sobre la teoría sexual. En Obras Completas, vol. 7, Amorrortu, Buenos Aires, 1978.

Freud, S. (1909). Análisis de la fobia de un niño de cinco años. En Obras Completas, vol. 10, Amorrortu, Buenos Aires, 1980.

Freud, S. (1910). Un recuerdo infantil de Leonardo da Vinci. En Obras Completas, vol. 11, Amorrortu, Buenos Aires, 1979.

Freud, S. (1918). De la historia de una neurosis infantil. En Obras Completas, vol. 17, Amorrortu, Buenos Aires, 1979.

Freud, S. (1920). Psicoanálisis de las masas y análisis del Yo. En Obras Completas, vol. 18, Amorrortu, Buenos Aires, 1979.

Freud, S. (1922). Sobre algunos mecanismos neuróticos en los celos, la paranoia y la homosexualidad. En Obras Completas, vol. 18, Amorrortu, Buenos Aires, 1979. 
Freud, S. (1935). Letter to an American mother, American Journal of Psychiatry, 1951, vol.107, p 787.

Freud, S. (1999). Correspondencia. Tomo II. Biblioteca Nueva, 1999. Bajo el cuidado de Nicolás Caparrós.

Freud, S. (1927). Fetichismo. En Obras Completas, vol. 21, Amorrortu, Buenos Aires, 1979.

Henry, G. (1935). Psychogenic and constitutional factors in homosexuality, Psychiatric Quarterly, vol. 8, pp. 243-264.

Hitschmann, E. (1911). Freud Neurosenlehre, Se cita la traducción inglesa, Freud's Theory of Neurosis, Moffat, Yard and Company, 1917

Isay, R. (1989). Being Homosexual: Gay Men and Their Development, New York, Avon Books.

Jones, E. (1953). The life and work of Sigmund Freud Vol. 3, Basic Books, 1953.

Kernberg, O. (1992). Aggression in Personality Disorders and Perversions, Yale University Press

Kernberg, O. (2002). Unresolved Issues in the Psychoanalytic Theory of Homosexuality and Bisexuality, Journal of Gay and Lesbian Psychotherapy, vol 6, pp 9-27.

Klein, M. (1932). The Psychoanalysis of Children, Grove Press. Se cita la edición del 1960.

Lewes, K. (1988). The Psychoanalytic Theory of Male Homosexuality, Simon \& Schuster.

Lingiardi, V. \& Capozzi, P. (2004). Psychoanalytic attitudes towards homosexuality: An empirical research, The International Journal of Psychoanalysis, vol. 85, pp 137-158.

Marmor, J. (1998). Homosexuality: Is Etiology Really Important?, Journal of Gay and Lesbian Psychotherapy, vol. 2, pp 19-28

Mitchell, S. (1978). Psychodynamics, Homosexuality, and the Question of Pathology, Psychiatry, vol. 41, pp 254-263.

Mitchell, S. (1997). Influence and Autonomy in Psychoanalysis, The Analytic Press. Se cita la edición del 2014.

Poe, J. (1952). The Successful Treatment of a 40-year Old Passive Homosexual Based on an Adaptational View of Sexual Behavior, Psychoanalytic Review, vol. 39, pp. 23-33.

Rado, S. (1940). A Critical Examination of the Concept of Bisexuality, Psychosomatic Medicine, vol. 4, pp. 459-467.

Rank, O. (1923). Perversion and Neurosis, International Journal of Psycho-Analysis, vol. 4, pp. 270-292.

Reich, W. (1932). Der Sexuelle Kampf der Jugend, Sexpol Verlag. Se cita la traducción inglesa, Children of the Future: On the Prevention of Sexual Pathology, Macmillan, 2013.

Rosenfeld, H. (1949). Remarks on the Relation of Male Homosexuality to Paranoia, Paranoid Anxiety and Narcissism, The International Journal of Psychoanalysis, vol. 30, pp. 36-47.

Roughton, R. (1993). Useful aspects of acting out: repetition, enactment, and actualization, Journal of the American Psychoanalytic Association, vol 41, pp 443-472. 
Schilder, P. (1942). Goals and Desires of Man, Columbia University Press.

Socarides, C. (1978). Homosexuality, International Review of Psycho-Analysis, vol. 10, pp. 488490.

Stekel, W. (1922). Onanie und Homosexualität. Die homosexuelle Parapathie, Gorham Press. Se cita la traducción inglesa, Bi-Sexual Love, Emerson Books, 1950.

Winterstein, A. (1956). On the Oral Basis of a Case of Male Homosexuality, International Journal of Psycho-Analysis, vol. 37, pp. 298-302.

Original recibido con fecha: 14/10/2018 Revisado: 24/10/2018 Aceptado: 30/10/2018 